\title{
EFFECT OF HONEY PROPOLIS HARD CANDY ON LACTOPEROXIDASE ACTIVITY IN UNSTIMULATED SALIVA
}

\author{
KARLA MONICA WIJAYA, SRI ANGKY SOEKANTO*, NURTAMI SOEDARSONO
}

\author{
Department of Oral Biology, Faculty of Dentistry, Universitas Indonesia, Jakarta, Indonesia. Email: sasoekanto@gmail.com
}

Received 8 October 2018, Revised and Accepted 11 January 2018

\begin{abstract}
Objective: We determined the effectiveness of honey propolis hard candy on salivary lactoperoxidase activity in unstimulated saliva.

Methods: In this pretest-posttest laboratory experimental design study, saliva collected from 120 subjects was reacted with potassium iodide, phosphate buffer, and hydrogen peroxide. Salivary lactoperoxidase activity was calculated by absorbance value using a microplate reader at wavelength of $340 \mathrm{~nm}$.
\end{abstract}

Results: Honey propolis hard candy increased salivary lactoperoxidase activity, although the increase was not statistically significant (p>0.05).

Conclusions: Honey propolis hard candy tends to increase salivary lactoperoxidase activity.

Keywords: Propolis, Lactoperoxidase, Saliva.

(C) 2019 The Authors. Published by Innovare Academic Sciences Pvt Ltd. This is an open access article under the CC BY license (http://creativecommons. org/licenses/by/4. 0/) DOI: http://dx.doi.org/10.22159/ijap.2019.v11s1.159

\section{INTRODUCTION}

According to basic of health research Republic of Indonesia 2013, the prevalence of dental caries in Indonesia has increased significantly to $43.4 \%$ in 2007 and $53.2 \%$ in 2013 [1]. Dental caries is the most common disease in the oral cavity, disrupting the quality of life and health of an individual. Some treatments have been performed to prevent dental caries, but this is rare in the Indonesian people. Hence, dental caries preventions are required that are more easily available to Indonesian people. A natural ingredient that may help prevent dental caries is propolis.

Propolis is a natural resin substance that is collected by bees from plant trunk and tree bark exudates and used to close the pathway to their nests [2]. Herbal ingredients have been used as alternative medicines for many years. Propolis contains naphthoquinone epoxide, prenylated acid, medicarpin, Vitamin A, Vitamin E, Vitamin B complex, flavonoid, polyphenol, phenolic aldehyde, quinine, coumarin, amino acid, steroid, and some other inorganic contents, depending on the location and time of harvest, and plant sources [3,4].

Propolis has known antibacterial, antioxidant, antiulcer, antitumor, antifungal, and anti-inflammatory functions [2,4]. Its role as an antibacterial and antioxidant is due to the flavonoid content [5]. Some products containing propolis include toothpaste, gum, soap, cream, and lotions [6]. At present, propolis is being formulated into hard candies, one of which is honey propolis hard candy made by the University of Indonesia.

Honey propolis hard candy has been proven to decrease the prevalence of Streptococcus mutans [7]. To understand more about the effectiveness of honey propolis hard candy as an antibacterial, we performed a lactoperoxidase activity test in saliva.

Lactoperoxidase is an enzyme produced from the peroxidase system (a non-specific immunity system) in saliva. The main function of peroxidase is oxidation catalyzation by thiocyanate of hydrogen peroxide $\left(\mathrm{H}_{2} \mathrm{O}_{2}\right)$ in saliva, so it has potential as an antibacterial. Human saliva contains two peroxidases (lactoperoxidase and myeloperoxidase) [8]. Lactoperoxidase is mostly found in human saliva [9].
Lactoperoxidase activity is affected by changes in the oral cavity, such as $\mathrm{H}_{2} \mathrm{O}_{2}$ concentration, thiocyanate ion $\left(\mathrm{SCN}^{-}\right)$concentration, $\mathrm{pH}$, and temperature [10], and also by the number of bacteria in the oral cavity. This is because pathogenic bacteria produce $\mathrm{H}_{2} \mathrm{O}_{2}$. Activity increases or decreases if the number of pathogenic microorganisms producing $\mathrm{H}_{2} \mathrm{O}_{2}$ increases or decreases [11]. Lactoperoxidase activity will increase when infection occurs. A study demonstrated higher lactoperoxidase activity in patients with than in those without dental caries [11]. Another study reported higher lactoperoxidase activity in patients with than in those without periodontitis [11]. Xylitol consumption, as an antibacterial, decreases lactoperoxidase activity [12]. Decreased lactoperoxidase activity after exposure to an antibacterial can affect oral health poorly due to the resultant decrease in the number of bacteria, which, in turn, can give other microorganisms, such as Candida albicans, a chance to develop. Therefore, a significant decrease in lactoperoxidase activity can disrupt the normal flora equilibrium in the oral cavity [13]. Lactoperoxidase activity can be used as an indicator for the effectiveness of propolis as an antibacterial, thus demonstrating whether an antibacterial can disrupt oral equilibrium.

We studied three types of candy: Honey propolis candy (containing propolis and honey), honey candy (containing honey only), and $\mathrm{X}$ propolis candy (containing propolis only but does not interfere with lactoperoxidase activity).

To the best of our knowledge, no study has been performed on the effect of propolis in a hard candy form on saliva lactoperoxidase activity. Therefore, this study was done to understand the effectiveness of propolis hard candy as an antibacterial on lactoperoxidase activity in saliva.

\section{METHODS}

This laboratory experimental pretest-posttest study was done in vivo on 120 students of the Faculty of Dentistry, Universitas Indonesia, from the $1^{\text {st }}$ to $6^{\text {th }}$ year classes of $2013 / 2014$. Inclusion criteria were good general health, good oral health, age 17-23 years, and provision of a signed informed consent to participate in the study until finish. Exclusion criteria were wearing orthodontic appliances, periodontal 
disease, smoking, wearing dentures, other systemic diseases, taking antibiotics, drinking alcohol, and allergy to propolis. The samples included unstimulated saliva before and after treatment. The study was done at the Oral Biology Laboratory, Faculty of Dentistry, Universitas Indonesia, from July to November 2014.

The subjects were divided into three groups. Groups A (40 subjects), B ( 40 subjects), and C ( 40 subjects) consumed honey propolis, honey, and $\mathrm{X}$ propolis hard candies, respectively, 2 times a day for 7 consecutive days. The candies were consumed for the full number of days.

Before sample taking, patients were instructed to brush their teeth, without using mouthwash and without eating or drinking (unless mineral water) anything for a minimum of $1.5 \mathrm{~h}$ before treatment. Unstimulated saliva was collected in $20 \mathrm{~mL}$ microcentrifuge tube.

Then, $1.5 \mathrm{~mL}$ sample of this saliva was centrifuged at $15.000 \mathrm{~g}$ at $4^{\circ} \mathrm{C}$ for 20 min until the supernatant was obtained [14]. $250 \mu \mathrm{L}$ supernatant was placed in a 96-well plate, and $500 \mu \mathrm{L}$ buffer solution containing potassium phosphate $\left(\mathrm{KH}_{2} \mathrm{PO}_{4}\right) \mathrm{pH} 6.0,250 \mu \mathrm{L}$ potassium iodide $(\mathrm{KI})$, and $100 \mu \mathrm{L} \mathrm{H}_{2} \mathrm{O}_{2} 40 \mathrm{mM}$ were added [15]. All samples were made in triplicate. A microplate reader was used with maximum capacity of $250 \mu \mathrm{L}$ in each microwell in the 96-well plate. Therefore, we used $50 \mu \mathrm{L}$ supernatant with $100 \mu \mathrm{L} \mathrm{KH}{ }_{2} \mathrm{PO} 4$ buffer solution $\mathrm{pH}$ 6.0, $50 \mu \mathrm{L} \mathrm{KI}$ $50 \mu \mathrm{mol}$, and $100 \mu \mathrm{L} \mathrm{H}_{2} \mathrm{O}_{2} 40 \mathrm{mM}$ added.

The microplate reader was calibrated and connected to the computer, so the results could be seen on the monitor. The 96-well plate was inserted in the microplate reader to measure the activity. The Microplate Manager program with the New Endpoint Protocol was used. Enzyme activity was read at $340 \mathrm{~nm}$ wavelength, and the results were displayed on the monitor as the absorbancy score for each microwell. This absorbancy score was used as a base to obtain data for further analysis.

Collected data were analyzed using SPSS 17 (SPSS, Inc., Chicago, IL, USA). Before processing, a Shapiro-Wilk normality test was done to determine the statistical values, due to data $<50$. A dependent t-test and the Wilcoxon test were used for normally and abnormally distributed data, respectively. To examine changes between before and after treatment among the three groups, one-way analysis of variance and Kruskal-Wallis tests were used for normally and abnormally distributed data, respectively.

\section{RESULTS}

The results of the Shapiro-Wilk normality test on lactoperoxidase activity data indicated that the data did not have a normal distribution. Therefore, a non-parametric statistical test was used. The Wilcoxon test was used to compare the average before-after treatment data in each group and the Kruskal-Wallis test was test used to compare the average before-after data from the three treatment groups.

Lactoperoxidase activity increased by approximately 0.00575 (nmol/L) in Group A (average before vs. after treatment, 0.01528 vs. 0.02103 ; Fig. 1, Table 1). The Wilcoxon test showed a significance of 0.706 ( $p>0.05)$. Therefore, there was no significant difference in lactoperoxidase activity between before and after treatment.

Lactoperoxidase activity increased by 0.00240 (nmol/L) in Group B (average before vs. after treatment, 0.01190 vs. 0.01430 ; Fig. 1). The Wilcoxon test showed a value of $0.700(p>0.05)$, which also was not significant (Table 1).
Lactoperoxidase activity decreased by 0.00783 (nmol/L) in Group C (average before vs. after treatment, 0.02083 vs. 0.01300; Fig. 1). The Wilcoxon test showed a value of $012(p<0.05)$, so this difference was significant. Then, the Kruskal-Wallis test revealed a value of 0.0219 ( $p>0.05)$, which demonstrated no significant difference in lactoperoxidase activity among the three groups.

\section{DISCUSSION}

We evaluated the effect of the consumption of candy containing propolis on lactoperoxidase activity. There was no significant difference in lactoperoxidase activity in Groups A (honey propolis candy, 0.00575 increase) and B (honey only candy, 0.0024 increase). Meanwhile, a significant difference was noted in Group C (X propolis candy, 0.00783 decrease).

Lactoperoxidase activity can be affected by $\mathrm{SCN}^{-}, \mathrm{H}_{2} \mathrm{O}_{2}, \mathrm{pH}$, and temperature [10], as well as by excessive carbohydrate intake because carbohydrate intake, especially sucrose, can block the accumulation of $\mathrm{SCN}^{-}[16]$. In addition, the presence of glucose in saliva stimulates more $\mathrm{H}_{2} \mathrm{O}_{2}$ formation because glucose causes bacteria to produce more $\mathrm{H}^{+}$ from fermentation [9].

Honey propolis and honey hard candy did not significantly affect lactoperoxidase activity, so both hard candies were good for the oral cavity because they did not disrupt the normal flora equilibrium. However, these candies had a tendency to increase lactoperoxidase activity, which can be due to the honey and glucose contents. Honey can increase lactoperoxidase activity by raising $\mathrm{H}_{2} \mathrm{O}_{2}$ in saliva. Honey contains $1 \mathrm{~mm} / \mathrm{L} \mathrm{H}_{2} \mathrm{O}_{2}$. Glucose in honey also can affect glycolysis by bacteria, so more $\mathrm{H}^{+}$is produced and more $\mathrm{H}_{2} \mathrm{O}_{2}$ is formed. Glucose also can affect the glucose oxidation process, which also produces $\mathrm{H}_{2} \mathrm{O}_{2}$.

The increased lactoperoxidase activity was greater in Group A than in Group B because the propolis content in honey propolis hard candy formed an $\mathrm{H}_{2} \mathrm{O}_{2}$ compound as an inductor of DNA destruction in bacteria. The flavonoid propolis acts as a temporary electron carrier, which is accepted from metal transition ions and is forwarded to oxygen molecules to form superoxide $\left(\mathrm{O}_{2}^{-}\right)$and $\mathrm{H}_{2} \mathrm{O}_{2}$ [5]. If the $\mathrm{H}_{2} \mathrm{O}_{2}$ concentration increases, lactoperoxidase activity also increases [10]. The increased $\mathrm{H}_{2} \mathrm{O}_{2}$ can have a good impact on the oral cavity because it can cause a potential host defense by increasing lactoperoxidase capacity.

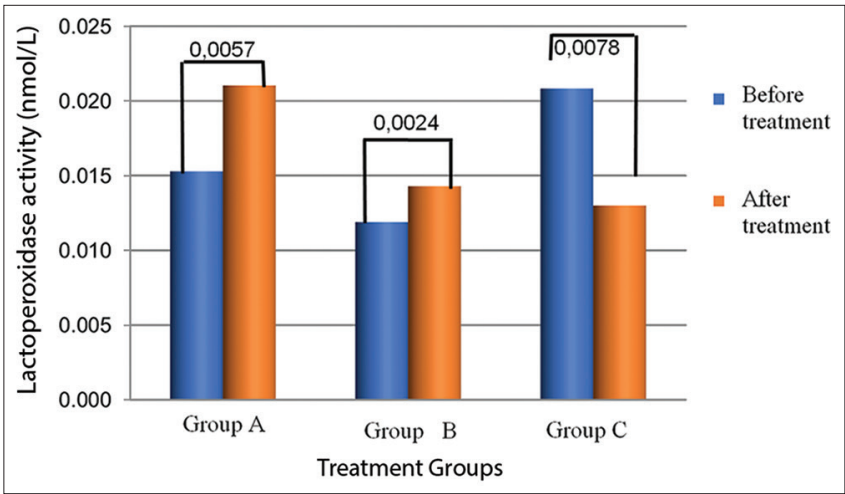

Fig. 1: Lactoperoxidase activity before and after treatment comparison in three groups

Table 1: Saliva lactoperoxidase activity score

\begin{tabular}{llll}
\hline Group & Before treatment average & After treatment average & p-value (Sig.) \\
\hline Group A $(n=40)$ Mean $\pm S D$ & $0.01528 \pm 0.015159$ & $0.02103 \pm 0.042073$ & 0.706 \\
Group B $(n=40)$ Mean \pm SD & $0.01190 \pm 0.011050$ & $0.01430 \pm 0.018509$ & 0.700 \\
Group C $(\mathrm{n}=40)$ Mean $\pm S D$ & $0.02083+0.028162$ & $0.01300 \pm 0.013640$ & 0.012 \\
\hline
\end{tabular}


However, our results are not in agreement with those of another study reporting that propolis functions as an antibacterial. Propolis functioning as an antibacterial also may decrease $\mathrm{H}_{2} \mathrm{O}_{2}$ concentration. Decreased numbers of bacteria result in decreased toxins from the bacteria such as $\mathrm{H}_{2} \mathrm{O}_{2}, \mathrm{H}_{2} \mathrm{~S}, \mathrm{H}^{+}$, and others. When salivary $\mathrm{H}_{2} \mathrm{O}_{2}$ concentration decreases, lactoperoxidase activity also decreases. Another study on honey propolis hard candy reported a decreased prevalence of $S$. mutans and $C$. albicans biofilm formation. A study on the effects of xylitol and mouthwash with betel water showed a change in lactoperoxidase activity $[17,18]$. Xylitol and betel have the same antibacterial effect as propolis. According to this study, lactoperoxidase activity should decrease with the use of honey propolis hard candy.

Our results also showed that honey propolis hard candy exposure in Group A did not significantly affect lactoperoxidase activity (although activity tended to increase), while activity decreased significantly in Group C (X propolis hard candy). Such a decrease could also disrupt the normal flora equilibrium in the oral cavity. The different effects of both candies also can be due to the honey content in honey propolis candy. Group A (honey propolis hard candy) contained honey, whereas Group C (X propolis hard candy) did not. The flavonoid and $\mathrm{H}_{2} \mathrm{O}_{2}$ in honey act as an antibacterial and antioxidant. As mentioned above, flavonoid can bind with $\mathrm{Fe}^{2+}$ ion and form $\mathrm{H}_{2} \mathrm{O}_{2}$ The concentration of $\mathrm{H}_{2} \mathrm{O}_{2}$ is high in honey (1 mmol/L) [19], and honey also has high osmolarity and low acidity (pH 3.2-4.5) [20]. OSCN ${ }^{-}$accumulation is more optimal at lower $\mathrm{pH}[20]$.

Honey propolis hard candy contained glucose syrup and sugar, whereas $\mathrm{X}$ propolis hard candy contained polydextrose. Glucose normally can be fermented by bacteria in the oral cavity, so it produces acid $\left(\mathrm{H}^{+}\right)$, which can bind with $\mathrm{O}_{2}^{-}$and form $\mathrm{H}_{2} \mathrm{O}_{2}$. Polydextrose is an artificial sweetener that often is used in foods and drugs. This artificial sweetener can disrupt reproduction, acid production, cell aggregation, and plaque formation of $S$. mutans, as well as its adherence to the teeth surface. Polydextrose also produces $20 \%$ lower acid than glucose, so it forms less $\mathrm{H}_{2} \mathrm{O}_{2}$ [21].

Propolis with fluoride showed good result in inhibit Streptococcus mutans and Enterobacter faecalis [22]. Soekanto et al showed that after mastication simulation using chewing gum of Casein PhosphopeptideAmorphous Calcium Phosphate -Propolis will increased calcium and phosphate ion level in caries-free saliva and decreased of $S$. mutans biofilm mass [23]. With this finding, it is necessary to further study and analyze the effectiveness of propolis in different combination to fight caries.

\section{CONCLUSIONS}

Honey propolis hard candy and honey candy did not affect lactoperoxidase activity significantly, but it had a tendency to increase activity. Meanwhile, X propolis hard candy decreased lactoperoxidase activity significantly.

\section{CONFLICTS OF INTEREST}

The authors report no conflicts of interest.

\section{REFERENCES}

1. Directorate Basic Health Serivices, Ministry of Health, Republic of Indonesia. Indonesia Oral Health Care Profile. Jakarta: Ministry of Health, Republic of Indonesia; 2014.
2. Coutinho A. Honeybee propolis extract in periodontal treatment: A clinical and microbiological study of propolis in periodontal treatment. Indian J Dent Res 2012;23:294.

3. Wagh VD. Review Article Propolis: A Wonder Bees Product and Its Pharmacological Potentials. Advances in Pharmacological Sciences Volume 2013, Article ID 308249, 1-11.

4. Khalil ML. Biological activity of bee propolis in health and disease. Asian Pac J Cancer Prev 2006; 7:22-31.

5. Tsai YC, Wang YH, Liou CC, Lin YC, Huang H, Liu YC, et al. Induction of oxidative DNA damage by flavonoids of propolis: Its mechanism and implication about antioxidant capacity. Chem Res Toxicol 2012;25:191-6.

6. Burdock GA. Review of the biological properties and toxicity of bee propolis (propolis). Food Chem Toxicol 1998;36:347-63.

7. Gladea Z. The Effect of Consumption of Honey Propolis Candy on the Prevalence of Streptococcus mutans in Caries Patients. [Dissertation]. Jakarta; 2012.

8. Ihalin R, Loimaranta V, Tenovuo J. Origin, structure, and biological activities of peroxidases in human saliva. Arch Biochem Biophys 2006; 445:261-8

9. Thomas EL, Bates KP, Jefferson MM. Peroxidase antimicrobial system of human saliva: Requirements for accumulation of hypothiocyanite. J Dent Res 1981;60:785-96.

10. Guentsch A, Preshaw PM, Bremer-Streck S, Klinger G, Glockmann E, Sigusch BW, et al. Lipid peroxidation and antioxidant activity in saliva of periodontitis patients: Effect of smoking and periodontal treatment. Clin Oral Investig 2008; 12:345-52.

11. Pruitt KM, Mansson-Rahemtulla B, Tenovuo J. Detection of the hypothiocyanite (OSCN-) ion in human parotid saliva and the effect of $\mathrm{pH}$ on OSCN-generation in the salivary peroxidase antimicrobial system. Arch Oral Biol 1983;28:517-25.

12. Lamberts BL, Pruitt KM, Pederson ED, Golding MP. Comparison of salivary peroxidase system components in caries-free and caries-active naval recruits. Caries Res 1984;18:488-94.

13. Alexander A. Prevention of Oral Health Diseases with LP-System [LPsystem Cegah Penyakit Gigi dan Mulut]; 2003. Available from: http:// www.kompas.com.

14. Benbahouche Nel H, Iliopoulos I, Török I, Marhold J, Henri J, Kajava AV, et al. Drosophila spag is the homolog of RNA polymerase II-associated protein 3 (RPAP3) and recruits the heat shock proteins 70 and 90 (Hsp70 and hsp90) during the assembly of cellular machineries. J Biol Chem 2014;289:6236-47.

15. Malesic J, Kolar J, Strlic M, Polanc S. The influence of halide and pseudo-halide antioxidants in fenton-like reaction systems. Acta Chim Slov 2006;53:450-6.

16. Thomas EL, Bates KP, Jefferson MM. Hypothiocyanite ion: Detection of the antimicrobial agent in human saliva. J Dent Res 1980;59:1466-72.

17. Mäkinen KK, Tenovuo J, Scheinin A. Xylitol-induced increase of lactoperoxidase activity. J Dent Res 1976;55:652-60.

18. Aisyiah S. Analysis of Effect of Water Gargles of Betel Leaves for 120 Seconds on Saliva Peroxidase Activity (with Comparison of 32 Grams of Betel Leaf and $100 \mathrm{ml}$ of Water). [Dissertation]. Jakarta; 2006.

19. Manisha M. Honey: Its medicinal property and antibacterial activity. Asian Pac J Trop Biomed 2011;1:154-60.

20. Kumar S, Debjit B. Medicinal uses and health benefits of honey: An overview. J Chem Pharmacol 2010;2:385-95.

21. Setsu E. Cariogenicity of polydextrose and refined polydextrose as a substrate. Nichidai Koko Kagaku 1989;15:1-11.

22. Soekanto SA, Marpaung LJ, Himmatushohwah, Djais A, Darwita RR. Efficacy of Propolis Fluoride and Nano Silver Fluoride for Inhibition of Streptococcus mutans and Enterococcus faecalis Biofilm Formation Int J App Pharm 2017;2:51-4

23. Soekanto SA, Ghrena GCD, Bachtiar EW, Sahlan M. The Effect Of Casein Phosphopeptide-Amorphous Calcium Phosphate-Propolis Chewing Gum On Calcium and Phosphate Ion Levels in Caries-Free Subject's Saliva and Streptococcus Mutans Biofilm Formation. Asian J Pharm Clin Res. 2017;174-6. 